\title{
Excess Body Weight and Gastroesophageal Reflux Disease
}

\author{
Andreas Thalheimer ${ }^{a, b} \quad$ Marco Bueter ${ }^{a, b}$ \\ a Department of Visceral and Transplant Surgery, University Hospital of Zürich, Zurich, Switzerland; \\ ${ }^{b}$ Department of Surgery, Spital Männedorf, Männedorf, Switzerland
}

\section{Keywords}

Obesity · Excess body weight · Reflux · Gastroesophageal reflux disease $\cdot$ Bariatric surgery

\begin{abstract}
Background: Gastroesophageal reflux disease (GERD) is strongly associated with excess body weight. Summary: GERD is characterized by typical symptoms with or without mucosal damage because of retrograde flow of gastric content into the esophagus. An ineffective esophagogastric junction (EGJ) combined with anatomical abnormalities is considered to be causative. The incidence of GERD is strongly associated with excess body weight, reflecting the pathophysiological relevance of the abdominothoracic pressure gradient. Key Message: Weight loss has been demonstrated to be an effective therapy for GERD combined with obesity. In cases in which surgical therapy is indicated, traditional antireflux surgery has led to equivocal results, advocating a proximal Roux-en-Y gastric bypass in these patients to correct both GERD and excess body weight.
\end{abstract}

(C) 2021 The Author(s)

Published by S. Karger AG, Basel

\section{Introduction}

Based on the Montreal classification, gastroesophageal reflux disease (GERD) is defined as a disease with symptoms and/or complications due to reflux of gastric content into the esophagus or beyond [1]. Cardinal symptoms of GERD include heartburn and regurgitation, though atypical symptoms like dysphagia, belching, epigastric pain, nausea, bloating, and extraesophageal symp- toms (e.g., cough, hoarseness, throat clearing, and sleep disturbances) may also occur [2]. The phenotypic presentation of GERD includes erosive esophagitis (EE), nonerosive reflux disease, and Barrett esophagus (BE) and tends to remain stable for the rest of the patients' life, while the frequency or severity of symptoms does not predict a specific phenotypic presentation of GERD $[3,4]$.

GERD is very common and affects up to one third of the general population and up to $70 \%$ of patients with severe obesity [5-7], highlighting its enormous medical and socioeconomic consequences [8]. The pathophysiology of GERD associated with or without severe obesity is characterized by functional and anatomical changes of the gastroesophageal junction (GEJ). Empiric treatment with a proton pump inhibitor (PPI) is usually the first therapy step in patients with typical symptoms. In patients with atypical symptoms, a lack of improvement following pharmacological treatment, or a reduced quality of life due to GERD-associated problems, extensive diagnostics are warranted [2], including an upper endoscopy, high-resolution manometry, and a catheter-based $24 \mathrm{~h}$ $\mathrm{pH}$ test with impedance measurement.

The increasing awareness of reflux problems in patients with excess body weight has led to an intensive discussion about the best therapy. Surgery, especially Rouxen-Y gastric bypass (RYGB) surgery, is gaining importance, in particular due to the increasing number of studies reporting the adverse effects of PPI therapy as well as the marked decline in the utilization of surgical fundoplication in patients with obesity.

The following review focuses on GERD in patients with excess body weight, with a special focus on the particularities of pathophysiology and treatment. mercial purposes requires written permission.
Correspondence to:

Andreas Thalheimer, andreas.thalheimer@usz.ch 


\section{Pathophysiology of GERD Associated with Excess Body Weight}

GERD is usually triggered by one of the following 4 mechanisms:

- Transient lower esophageal sphincter relaxations (tLESR)

- Decreased lower esophageal sphincter (LES) pressure

- Swallow-associated LES relaxation

- Straining during periods of low LES pressure.

The LES is an area of high pressure at the distal esophagus. The sphincter consists of circular and longitudinal layers of muscles. On the right side, the circular muscle layer is incomplete and forms semicircular muscle loops, also known as clasp fibers. On the left side, the incomplete muscle layers there pull into the gastric muscle loops and form an oblique, esophagogastric sphincter apparatus [9].

In patients without a hiatal hernia, tLESR are considered the most important mechanism of reflux during periods of normal LES pressure. Transient LESR occur independently of deglutition, induce inhibition of the diaphragmatic crural clamp, and persist for longer than normal relaxations in the context of normal swallowing [10]. Distention of the proximal stomach has been suggested to be the most important stimulus for tLESR. The dorsal motor nuclei of the vagal nerve lead to activation of inhibitory neurons in the distal esophagus by stimulation of vagal afferents in the distended stomach with subsequent activation of the brainstem. A complex interaction of inhibitory reflex responses, longitudinal muscle contraction, crural diaphragmatic inhibition, and contraction of the costal diaphragm finally leads to a tLESR reflex $[10,11]$.

In patients with a hiatal hernia, GERD is associated with a low LES pressure, swallow-associated relaxation of the LES, and possible straining during periods of low LES pressure, highlighting the pathophysiological relevance of an increased abdominothoracic pressure gradient for GERD development. Strain-induced reflux occurs via an acute or chronic increase in intra-abdominal pressure (IAP), leading to opening of a hypotensive LES. A pressure $>10 \mathrm{~mm} \mathrm{Hg}$ in the LES is supposed to safely prevent a retrograde reflux of gastric content to the esophagus. Values $<5 \mathrm{~mm} \mathrm{Hg}$ during the end expiratory phase are considered abnormal [12]. Thus, the integrity of the esophagogastric junction (EGJ) as an important antireflux barrier depends on the intactness of both the intrinsic LES and the diaphragmatic hiatus.

In patients with excess body weight, the integrity of the EGJ is threatened in particular due to the anatomical derangement of the EGJ by the presence of a hiatal hernia with a subsequent reduction of LES pressure. The prevalence of a hiatus hernia is much higher in subjects with excess body weight than in those with a normal body weight. Suter et al. [13] investigated 345 patients scheduled for bariatric surgery (BS) and found a hiatal hernia in more than $50 \%$ of patients endoscopically. These data were recently confirmed by a group from Taiwan, which reported a hiatal hernia in $33 \%$ of patients with morbid obesity, using high-resolution impedance manometry, while the hiatal hernia prevalence was $0 \%$ in a normalweight control group. Of note, all patients with hiatal hernia also showed an EE during endoscopy. As BMI and waist circumference were correlated to the vertical separation of the high-pressure zone of the LES and the crural diaphragm, the authors hypothesized a crucial role of pressure stress due to an increased intragastric volume [14].

Besides being associated with a higher prevalence of hiatal hernias and subsequent functional impairment of the EGJ, obesity has also been shown to be associated with a higher IAP combined with an increased abdominothoracic pressure gradient. In fact, measurements revealed IAP levels of up to $12 \mathrm{~cm} \mathrm{H}_{2} \mathrm{O}$ or $9 \mathrm{~mm} \mathrm{Hg}$ in patients with morbid obesity $[15,16]$, possibly leading to reflux of gastric content into the esophagus especially if a hiatal hernia with a concomitant reduced LES pressure is present.

The waist-hip-ratio represents an anthropometric parameter for the extent of visceral adipose tissue. Higher levels are associated with the presence of several metabolic comorbidities associated with morbid obesity, such as type 2 diabetes mellitus or cardiovascular disease [17]. Unsurprisingly, higher waist-hip-ratios are also associated with an increased IAP and subsequently with increased esophageal acid exposure and impaired esophageal acid clearance [18]. This observation is in accordance with reports demonstrating that women with obesity who are known to have less visceral adipose tissue, secrete less gastric acid, and tend to have less esophageal reflux than male subjects with obesity [19]. Moreover, visceral fat has been found to secrete adipocytokines like interleukin-6 and tumor necrosis factor- $\alpha$ which, among others, are thought to be involved in GERD pathogenesis and subsequent carcinogenesis.

Taken together, all of the above-mentioned factors and mechanisms clearly indicate that excess body weight is not only associated with GERD but may even be the main cause of its development in subjects with morbid obesity.

\section{Treatment of GERD in Patients with Excess Body Weight}

\section{Conservative Treatment Options}

Though not specific to individuals with obesity, means such as elevation of the head of the bed and specific deep- 
breathing exercises with a change from thoracic to $a b-$ dominal breathing are generally recommended in patients with GERD [20]. In patients with excess body weight, lifestyle management with a special focus on weight loss can also lead to reduction of GERD symptoms, while dietary advice should emphasize the reduction of dietary high saturated fat, cholesterol, and fat servings [21, 22].

Besides lifestyle modifications, a variety of medications can be used in the treatment of GERD. Antacids, $\mathrm{H}_{2}$ receptor antagonists, and PPI are the cornerstones of pharmacological GERD treatment. However, data on the efficacy of PPI in patients with obesity and GERD are equivocal, especially regarding the dosage of PPI [23]. Several studies have reported that doubling the dosage of PPI in obese or overweight patients may provide better GERD-specific symptom control compared to the standard dosage $[23,24]$.

Emerging research suggests that long-term PPI therapy may be associated with adverse events or complications such as acute kidney injury, chronic kidney disease, Clostridium difficile-induced diarrhea, infection, and osteoporosis. However, it must also be said that the actual risk of drug-associated side effects is relatively moderate. Most studies reporting side effects are population based, and it is unclear whether any of these reports will be confirmed in a prospective trial [2].

Nevertheless, the US Food and Drug Administration (FDA) has issued several safety announcements urging health care professionals to perform reasonable risk-benefit considerations when prescribing PPI [25].

\section{Surgical Treatment Options}

Fundoplication

Laparoscopic antireflux surgery is an established therapy alternative to lifelong pharmacological acid suppression in patients with GERD. Varieties of fundoplication procedures for reinforcement of a dysfunctional LES have been described. The 2 most common procedures, i.e., Nissen fundoplication and Toupet fundoplication, have been shown to be effective and safe $[26,27]$. The efficacy of these procedures in patients with obesity, however, is a matter of debate.

Many studies focusing on the outcome of different fundoplication techniques in patients with obesity and GERD have shown not only satisfactory reflux control but also similar results in patient satisfaction and the frequency of adverse events compared to nonobese patients with GERD - at least in the short term [28, 29]. However, the safety and efficacy of laparoscopic antireflux surgery in obese patients is controversial as other studies indicate that obesity may represent a risk factor for GERD recurrence, dissatisfaction, or persistent severe symptoms after laparoscopic antireflux surgery [30, 31].
A recently performed systematic review and metaanalysis compared the outcomes after laparoscopic antireflux surgery in patients with and without obesity [32]. Based on the available evidence, the authors concluded that laparoscopic antireflux surgery can be safely performed in patients with obesity with similar postoperative complication rates compared to patients with a normal body weight. However, there was also a higher risk of recurrence of reflux symptoms following fundoplication in patients with excess body weight.

This is in accordance with previous studies reporting reflux recurrence rates of up to $30 \%$ in mid- and longterm follow-up in patients with obesity who underwent antireflux surgery $[30,33]$. A small series including patients with morbid obesity who underwent revisional antireflux surgery due to failed fundoplication showed that failure was most often related to wrap disruption [34], suggesting a causative role of persisting obesity with concomitant increased IAP by stretching of the wrap.

\section{Roux-en-Y Gastric Bypass}

Given the conflicting results of traditional antireflux surgery in patients with excess body weight, BS has received increased attention as a treatment option for GERD in patients with morbid obesity. BS not only leads to significant weight loss but also reduces the abdominothoracic pressure gradient, a major pathophysiologic element of GERD. Already 30 years ago, the RYGB had been shown to be a highly effective surgical therapy in severely obese GERD patients, with $97 \%$ of patients being asymptomatic postoperatively [35]. These excellent results were confirmed in several studies demonstrating relief of subjective esophageal and extraesophageal symptoms in more than $90 \%$ of obese patients after RYGB. Postoperative absence of symptoms also led to a significant reduction or termination of the necessary PPI medication in these patients [36, 37].

In addition to a subjective relief of GERD symptoms, it has been shown that RYGB surgery also leads to an objective improvement of symptoms such as reduced pathologic acid levels in the esophagus. For example, Madalosso et al. [38] demonstrated that the total esophageal acid exposure was reduced in patients with obesity and GERD from 5.1 to $1.1 \%$ after RYGB. Other studies showed an even more pronounced reduction in the pre- to postoperative change in acid exposure [39].

However, the sensation of acid exposure within the esophagus varies significantly between patients. A subgroup of GERD patients, for example, is credibly reported to suffer from typical esophageal symptoms which cannot be objectified by a pH-metry or other standard reflux metrics. On the other hand, there are patients who are completely unaware of symptoms related to acid exposure in the esophagus, with pathological changes of 
the gastroesophageal junction remaining unnoticed. The incidence of $\mathrm{BE}$ in patients with obesity ranges from 1.3 to $3.8 \%$, which is at least twice the prevalence of $\mathrm{BE}$ reported in the general population [40]. It is important to realize that almost $50 \%$ of these patients do not have symptoms. A recently published systematic review showed that RYGB is associated with postoperative regression of $\mathrm{BE}$ and dysplasia in 36-62\% of patients with preoperative confirmed BE [41]. The fact that gastric bypass is highly effective in improving both subjective and objective problems of reflux disease demonstrates its special role in the therapy of GERD in severely overweight patients.

RYGB is beneficial for patients with excess body weight and GERD due to a variety of mechanisms. First, RYGB leads to significant weight loss which results in a decreased IAP and a lower thoracic-abdominal pressure gradient. Second, the creation of a small gastric pouch diverts the majority of the acidic gastric content distally and thereby decreases the esophageal acid exposure. Gastric emptying in the pouch is accelerated compared to an intact stomach, further contributing to the decrease in esophageal acid exposure. Finally, bile reflux is prevented by the post-RYGB gastrointestinal anatomy [42].

If a hiatal hernia is also present, it should be treated by means of a hiatoplasty during gastric bypass surgery. In a recent study, the simultaneous treatment of a hiatal hernia was not associated with an increased complication rate following gastric bypass surgery [43]. Furthermore, reconstruction of the EGJ might be important for a sufficient pouch anatomy.

Against this background, it is not surprising that the Society of American Gastrointestinal and Endoscopic Surgeons (SAGES) recommends RYGB as the gold-standard surgical treatment in a population with GERD and excess body weight $(\mathrm{BMI}>35)$ [42]. The German guidelines from 2014 did not yet consider RYGB for surgical treatment of this patient population [44]. However, this may be corrected in the updated revision, which is expected to be published soon.

In this context, it must be emphasized again that all patients after gastric bypass surgery, be it due to primary obesity or due to GERD associated with excess body weight, need close, lifelong, and interdisciplinary followup care in order to deal with any problems after bypass surgery.

\section{Sleeve Gastrectomy}

Whereas the majority of data on reflux outcomes following RYGB is promising and positive, the data regarding GERD in patients following laparoscopic sleeve gastrectomy (LSG) tend to be unfavorable. LSG has gained popularity in the treatment of obesity due to its efficacy and safety profile without strongly affecting the anatomy and function of the foregut. With more than 55\% of all primary bariatric surgical procedures worldwide, LSG continues to enjoy great popularity [45]. With regard to GERD following LSG, published data suggest no improvement in symptoms or even development of de novo GERD postoperatively [46]. The mechanisms supporting the hypothesis of LSG inducing gastroesophageal reflux include an increase in intragastric pressure due to elimination of the distensible fundus and alterations in the angle of His with disruption of the gastric sling fibers leading to a decrease in the basal pressure of the LES $[47,48]$. Remarkably, objective physiologic studies have demonstrated a postoperative worsening of GERD following LSG with an increase in both acid exposure to the distal esophagus and number of non-acid reflux episodes postprandial [49]. A recently published systematic review and meta-analysis appraising the prevalence of GERD, esophagitis, and BE after LSG demonstrated de novo reflux in $23 \%$, esophagitis in $30 \%$, and $\mathrm{BE}$ in $8 \%$ of patients postoperatively [50]. Considering all of these data, LSG is not recommended for the treatment of GERD in patients with excess body weight and obviously seems to be an inferior option in this population [42].

\section{Conclusion}

The pathophysiology of GERD is different in lean and obese individuals. Excess body weight with a concomitant high incidence of hiatal hernia leads to derangement of the EGJ by weakening of both the diaphragmatic hiatus and the LES. The obesity-related increase in IAP with deterioration of the thoracic-abdominal pressure gradient further aggravates the reflux of gastric content into the esophagus with increased exposure of acid.

Weight loss is the most important therapeutic approach for the treatment of reflux disease in patients with excess body weight. Since conservative therapeutic approaches for the treatment of excess body weight often do not lead to a persistent reduction in weight, BS is of particular importance in obesity-associated GERD. This is even more true because traditional antireflux surgery has produced equivocal results in patients with obesity. The RYGB is considered the gold standard in the surgical treatment of GERD in obese patients, especially since sleeve gastrectomy, often worsens a preexisting GERD or leads to de novo GERD in a significant number of patients.

\section{Conflict of Interest Statement}

The authors have no conflict of interests to declare. 


\section{Funding Sources}

The authors do not have funding sources.

\section{Author Contribution}

A.T. was responsible for drafting and writing this paper. M.B. is responsible for drafting and reviewing this paper.

\section{References}

1 Vakil N, van Zanten SV, Kahrilas P, Dent J, Jones R; Global Consensus Group. The Montreal definition and classification of gastroesophageal reflux disease: a global evidencebased consensus. Am J Gastroenterol. 2006 Aug;101(8):1900-20.

2 Sandhu DS, Fass R. Current Trends in the Management of Gastroesophageal Reflux Disease. Gut Liver. 2018 Jan;12(1):7-16.

3 Fass R. Non-erosive reflux disease (NERD) and erosive esophagitis-a spectrum of disease or special entities? Z Gastroenterol. 2007 Nov;45(11):1156-63.

4 Fass R, Ofman JJ. Gastroesophageal reflux disease-should we adopt a new conceptual framework? Am J Gastroenterol. 2002 Aug; 97(8):1901-9.

5 Sharara AI, Rustom LB, Bou Daher H, Rimmani HH, Shayto RH, Minhem M, et al. Prevalence of gastroesophageal reflux and risk factors for erosive esophagitis in obese patients considered for bariatric surgery. Dig Liver Dis. 2019 Oct;51(10):1375-9.

6 El-Serag HB, Ergun GA, Pandolfino J, Fitzgerald S, Tran T, Kramer JR. Obesity increases oesophageal acid exposure. Gut. 2007 Jun; 56(6):749-55.

7 El-Serag HB, Sweet S, Winchester CC, Dent J. Update on the epidemiology of gastro-oesophageal reflux disease: a systematic review. Gut. 2014 Jun;63(6):871-80.

8 Weihs C, Madisch A, Schlaud M, Heimann D, Meyer H, Hotz J. Socioepidemic analysis of sources of information and medical care for a subpopulation of female and male participants in a nationwide informative campaign in Germany on "Danger Signal: heartburn". Gesundheitswesen. 2003 Jun;65(6):402-8

9 Bajwa SA, Toro F, Kasi A. Physiology, Esophagus. Treasure Island (FL): StatPearls; 2021.

10 Roman S, Holloway R, Keller J, Herbella F, Zerbib F, Xiao Y, et al. Validation of criteria for the definition of transient lower esophageal sphincter relaxations using high-resolution manometry. Neurogastroenterol Motil. 2017 Feb;29(2):e12920.

11 Mittal RK, Karstens A, Leslie E, et al. Ambulatory high-resolution manometry, lower esophageal sphincter lift and transient lower esophageal sphincter relaxation. Neurogastroenterol Motil. 2012 Jan;24(1):40-6, e2.

12 Pandolfino JE, Kim H, Ghosh SK, Clarke JO, Zhang Q, Kahrilas PJ. High-resolution manometry of the EGJ: an analysis of crural diaphragm function in GERD. Am J Gastroenterol. 2007 May;102(5):1056-63.

13 Suter M, Dorta G, Giusti V, Calmes JM. Gastro-esophageal reflux and esophageal motility disorders in morbidly obese patients. Obes Surg. 2004 Aug;14(7):959-66.
14 Yen HH, Tseng PH, Shih MC, Yang PJ, Lin MT, Lee PC. Derangement of esophageal anatomy and motility in morbidly obese patients: a prospective study based on high-resolution impedance manometry. Surg Obes Relat Dis. 2020 Dec;16(12):2006-15.

15 Varela JE, Hinojosa M, Nguyen N. Correlations between intra-abdominal pressure and obesity-related co-morbidities. Surg Obes Relat Dis. 2009 Sep-Oct;5(5):524-8.

16 Lambert DM, Marceau S, Forse RA. Intra-abdominal pressure in the morbidly obese. Obes Surg. 2005 Oct;15(9):1225-32.

17 Stefan N. Causes, consequences, and treatment of metabolically unhealthy fat distribution. Lancet Diabetes Endocrinol. 2020 Jul; 8(7):616-27

18 Ringhofer C, Lenglinger J, Riegler M, Kristo I, Kainz A, Schoppmann SF. Waist to hip ratio is a better predictor of esophageal acid exposure than body mass index. Neurogastroenterol Motil. 2017 Jul;29(7):e13033.

19 Ter RB. Gender differences in gastroesophageal reflux disease. J Gend Specif Med. 2000 Mar-Apr;3(2):42-4.

20 Eherer A. Management of gastroesophageal reflux disease: lifestyle modification and alternative approaches. Dig Dis. 2014;32(1-2): 149-51.

21 Ness-Jensen E, Hveem K, El-Serag H, et al. Lifestyle Intervention in Gastroesophageal Reflux Disease. Clin Gastroenterol Hepatol. 2016;14(2):175-82 e1-3.

22 El-Serag HB, Satia JA, Rabeneck L. Dietary intake and the risk of gastro-oesophageal reflux disease: a cross sectional study in volunteers. Gut. 2005 Jan;54(1):11-7.

23 Becker V, Grotz S, Schlag C, Nennstiel S, Beitz A, Haller B, et al. Positive predictors for gastroesophageal reflux disease and the therapeutic response to proton-pump inhibitors. World J Gastroenterol. 2014 Apr;20(14): 4017-24.

24 Chen WY, Chang WL, Tsai YC, Cheng HC, Lu CC, Sheu BS. Double-dosed pantoprazole accelerates the sustained symptomatic response in overweight and obese patients with reflux esophagitis in Los Angeles grades A and B. Am J Gastroenterol. 2010 May;105(5): 1046-52.

25 Maret-Ouda J, Markar SR, Lagergren J. Gastroesophageal Reflux Disease: A Review. JAMA. 2020 Dec;324(24):2536-47.

26 Broeders JA, Mauritz FA, Ahmed Ali U, Draaisma WA, Ruurda JP, Gooszen HG, et al. Systematic review and meta-analysis of laparoscopic Nissen (posterior total) versus Toupet (posterior partial) fundoplication for gastro-oesophageal reflux disease. Br J Surg. 2010 Sep;97(9):1318-30.
27 Andreou A, Watson DI, Mavridis D, Francis NK, Antoniou SA. Assessing the efficacy and safety of laparoscopic antireflux procedures for the management of gastroesophageal reflux disease: a systematic review with network meta-analysis. Surg Endosc. 2020 Feb;34(2): 510-20.

28 Anvari M, Bamehriz F. Outcome of laparoscopic Nissen fundoplication in patients with body mass index >or=35. Surg Endosc. 2006 Feb;20(2):230-4.

29 Chisholm JA, Jamieson GG, Lally CJ, Devitt PG, Game PA, Watson DI. The effect of obesity on the outcome of laparoscopic antireflux surgery. J Gastrointest Surg. 2009 Jun;13(6): 1064-70.

30 Tekin K, Toydemir T, Yerdel MA. Is laparoscopic antireflux surgery safe and effective in obese patients? Surg Endosc. 2012 Jan;26(1): 86-95.

31 Morgenthal CB, Lin E, Shane MD, Hunter JG, Smith CD. Who will fail laparoscopic Nissen fundoplication? Preoperative prediction of long-term outcomes. Surg Endosc. 2007 Nov; 21(11):1978-84.

32 Abdelrahman T, Latif A, Chan DS, Jones H, Farag M, Lewis WG, et al. Outcomes after laparoscopic anti-reflux surgery related to obesity: A systematic review and meta-analysis. Int J Surg. 2018 Mar;51:76-82.

33 Perez AR, Moncure AC, Rattner DW. Obesity adversely affects the outcome of antireflux operations. Surg Endosc. 2001 Sep;15(9):9869.

34 Kellogg TA, Andrade R, Maddaus M, Slusarek B, Buchwald H, Ikramuddin S. Anatomic findings and outcomes after antireflux procedures in morbidly obese patients undergoing laparoscopic conversion to Roux-en-Y gastric bypass. Surg Obes Relat Dis. 2007 JanFeb;3(1):52-7.

35 Jones KB Jr, Allen TV, Manas KJ, McGuinty DP, Wilder WM, Wadsworth ED. Roux-Y Gastric Bypass: an effective anti-reflux procedure. Obes Surg. 1991 Sep;1(3):295-8.

36 Smith SC, Edwards CB, Goodman GN. Symptomatic and clinical improvement in morbidly obese patients with gastroesophageal reflux disease following Roux-en-Y gastric bypass. Obes Surg. 1997 Dec;7(6):479-84.

37 Frezza EE, Ikramuddin S, Gourash W, Rakitt T, Kingston A, Luketich J, et al. Symptomatic improvement in gastroesophageal reflux disease (GERD) following laparoscopic Rouxen-Y gastric bypass. Surg Endosc. 2002 Jul; 16(7):1027-31

38 Madalosso CA, Gurski RR, Callegari-Jacques SM, Navarini D, Mazzini G, Pereira MS. The Impact of Gastric Bypass on Gastroesophageal Reflux Disease in Morbidly Obese Patients. Ann Surg. 2016 Jan;263(1):110-6. 
39 Mejía-Rivas MA, Herrera-López A, Hernández-Calleros J, Herrera MF, Valdovinos MA. Gastroesophageal reflux disease in morbid obesity: the effect of Roux-en-Y gastric bypass. Obes Surg. 2008 Oct;18(10):1217-24.

40 Runge TM, Abrams JA, Shaheen NJ. Epidemiology of Barrett's Esophagus and Esophageal Adenocarcinoma. Gastroenterol Clin North Am. 2015 Jun;44(2):203-31.

41 Goonawardena J, Ward S. Effect of Roux-enY gastric bypass on Barrett's esophagus: a systematic review. Surg Obes Relat Dis. 2021 Jan; 17(1):221-30

42 Nau P, Jackson HT, Aryaie A, Ibele A, Shouhed D, Lo Menzo E, et al.; SAGES Foregut Task Force White Paper. Surgical management of gastroesophageal reflux disease in the obese patient. Surg Endosc. 2020 Jan 34(1):450-7.
43 Lewis KH, Callaway K, Argetsinger S, Wallace J, Arterburn DE, Zhang F, et al. Concurrent hiatal hernia repair and bariatric surgery: outcomes after sleeve gastrectomy and Roux-enY gastric bypass. Surg Obes Relat Dis. 2021 Jan;17(1):72-80.

44 Koop H, Fuchs KH, Labenz J, Lynen Jansen P, Messmann H, Miehlke S, et al.; Mitarbeiter der Leitliniengruppe. [S2k guideline: gastroesophageal reflux disease guided by the German Society of Gastroenterology: AWMF register no. 021-013]. Z Gastroenterol. 2014 Nov;52(11):1299-346.

45 Angrisani L, Santonicola A, Iovino P, Ramos A, Shikora S, Kow L. Bariatric Surgery Survey 2018: Similarities and Disparities Among the 5 IFSO Chapters. Obes Surg. 2021 Jan;31: 1937-48.

46 Chern TY, Chan DL, Maani J, et al. High-resolution impedance manometry and 24-hour multichannel intraluminal impedance with $\mathrm{pH}$ testing before and after sleeve gastrectomy: de novo reflux in a prospective series. Surg Obes Relat Dis. 2021 Feb;17(2):329-37.
47 Braghetto I, Lanzarini E, Korn O, Valladares $\mathrm{H}$, Molina JC, Henriquez A. Manometric changes of the lower esophageal sphincter after sleeve gastrectomy in obese patients. Obes Surg. 2010 Mar;20(3):357-62.

48 Daes J, Jimenez ME, Said N, Daza JC, Dennis R. Laparoscopic sleeve gastrectomy: symptoms of gastroesophageal reflux can be reduced by changes in surgical technique. Obes Surg. 2012 Dec;22(12):1874-9.

49 Del Genio G, Tolone S, Limongelli P, Brusciano L, D'Alessandro A, Docimo G, et al. Sleeve gastrectomy and development of "de novo" gastroesophageal reflux. Obes Surg. 2014 Jan;24(1):71-7.

50 Yeung KT, Penney N, Ashrafian L, Darzi A, Ashrafian H. Does Sleeve Gastrectomy Expose the Distal Esophagus to Severe Reflux? A Systematic Review and Meta-analysis. Ann Surg. 2020 Feb;271(2):257-65. 